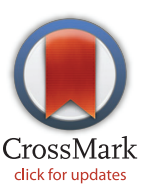

click for updates
RESEARCH ARTICLE

\section{Morphological Characteristics, Anatomical Structure, and Gene Expression: Novel Insights into Cytokinin Accumulation during Carrot Growth and Development}

\author{
Guang-Long Wang ${ }^{1}$, Sheng Sun ${ }^{2}$, Guo-Ming Xing ${ }^{2}$, Xue-Jun Wu${ }^{1}$, Feng Wang ${ }^{1}$, Ai- \\ Sheng Xiong ${ }^{1 *}$
}

1 State Key Laboratory of Crop Genetics and Germplasm Enhancement, College of Horticulture, Nanjing Agricultural University, Nanjing, 210095, China, 2 College of Horticulture, Shanxi Agricultural University, Taigu, 030801, China

* xiongaisheng@njau.edu.cn

\section{Abstract}

Cytokinins have been implicated in normal plant growth and development. These bioactive molecules are essential for cell production and expansion in higher plants. Carrot is an Apiaceae vegetable with great value and undergoes significant size changes over the process of plant growth. However, cytokinin accumulation and its potential roles in carrot growth have not been elucidated. To address this problem, carrot plants at five stages were collected, and morphological and anatomical characteristics and expression profiles of cytokinin-related genes were determined. During carrot growth and development, cytokinin levels were the highest at the second stage in the roots, whereas relatively stable levels were observed in the petioles and leaves. DcCYP735A2 showed high expression at stage 2 in the roots, which may contribute largely to the higher cytokinin level at this stage. However, expression of most metabolic genes did not follow a pattern similar to that of cytokinin accumulation, indicating that cytokinin biosynthesis was regulated through a complex network. Genes involved in cytokinin signal perception and transduction were also integrated to normal plant growth and development. The results from the present work suggested that cytokinins may regulate plant growth in a stage-dependent manner. Our work would shed novel insights into cytokinin accumulation and its potential roles during carrot growth. Further studies regarding carrot cytokinins may be achieved by modification of the genes involved in cytokinin biosynthesis, inactivation, and perception.

\section{Introduction}

Hormones are intrinsic plant growth regulators that act in response to environmental cues $[1,2]$. Among them, cytokinins (CKs) are a group of phytohormones that are involved in various aspects of plant growth, including reproductive development, seed germination, leaf 
collection and analysis, decision to publish, or preparation of the manuscript.

Competing Interests: The authors have declared that no competing interests exist. senescence, photomorphogenesis, and meristem activity [3-5]. Naturally occurring CKs include isoprenoid CKs and aromatic CKs, although whether aromatic CKs are ubiquitous in all plants remains unclear [6].

The CK biosynthesis, degradation, and signaling pathways have been extensively studied in Arabidopsis [7,8] (Fig 1). Biosynthesis of iP-CKs (iP) and tZ-CKs (tZ) is initiated by a rate-limiting step, which is catalyzed by isopentenyl transferases (IPTs) $[9,10]$. Consequently, iP-nucleotides (iPRTP, iPRDP, and iPRMP) are converted to the corresponding tZ-nucleotides (tZRTP, tZRDP, and tZRMP) by cytochrome P450 monooxygenases (CYP735As) [11]. The

A

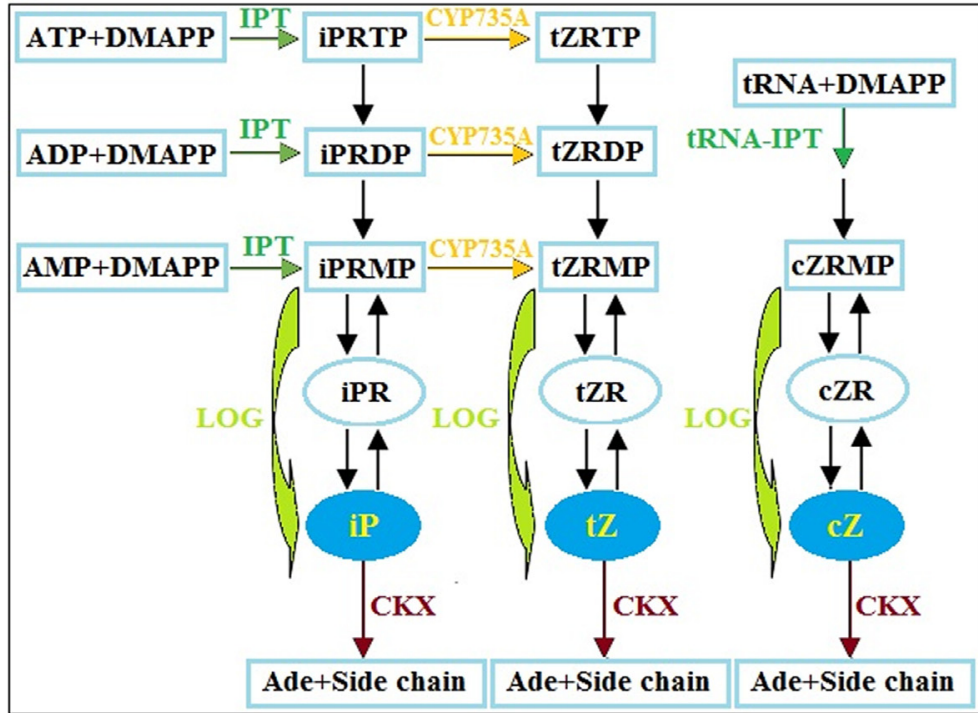

B

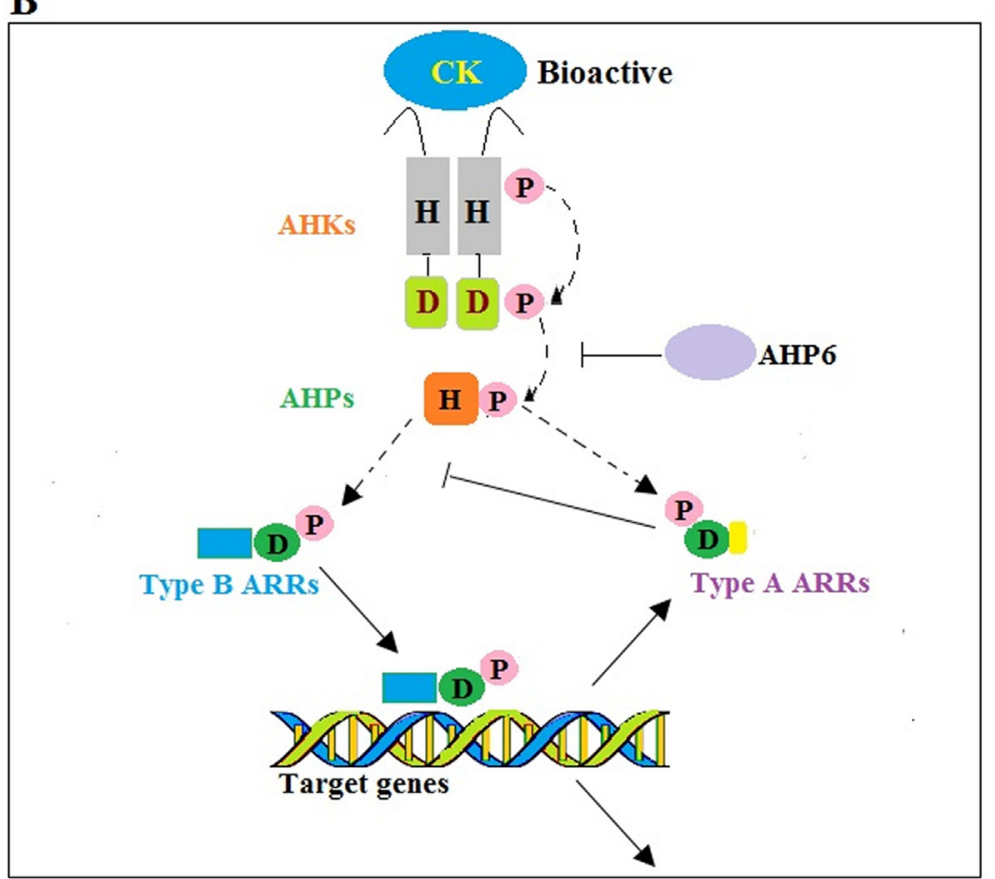

Fig 1. Proposed module of GA biosynthesis, inactivation, and perception in Arabidopsis.

doi:10.1371/journal.pone.0134166.g001 
conversion of active free bases is catalyzed by CK nucleoside $5^{\prime}$-monophosphate phosphoribohydrolases (LOGs) using monophosphates (iPRMP or tZRMP) as substrates [12]. iP and $\mathrm{tZ}$ are recognized as the most active CKs in most plants, including Arabidopsis. However, in some plant species, such as maize or rice, cis-zeatin CKs (cZ) that utilize tRNAs as prenyl acceptors are the major CK metabolites [13]. These bioactive CKs can be inactivated by CK dehydrogenases (CKXs) [14] (Fig 1A). In recent years, the CK signaling pathway has been proposed based on the identification of Arabidopsis mutants [15]. As previously described, CK conveys information through a complex two-component system [16]. In this model, CK binds to a CHASE domain of histidine kinase receptors (AHKs) and triggers a phosphorelay [17]. First, autophosphorylation occurs within the AHK receptor. The phosphoryl group is then transferred to nuclear response regulators (ARRs) via five histidine phosphotransfer proteins (AHP1-AHP5) [18]. AHP6, a pseudo AHP, impairs phosphotransfer by competing with AHP1-AHP 5 [19]. Two types of ARRs, type-A and type-B, exist. The phosphorylated type-B ARRs can bind DNA and activate the transcription of CK-regulated targets, including the type-A ARRs, which act as negative regulators of CK signaling [20] (Fig 1B).

Numerous studies have indicated that plant growth can be controlled by regulating the CKrelated genes [21-23]. Carrot (Daucus carota L.) is an Apiaceae plant with great value [24]. CarrotDB, a genomic and transcriptomic database has been well established [25,26]. Carrot development involves successive changes in organ size, metabolism, and physiological processes $[27,28]$. This process is essential for carrot production and quality and has been an area of increasing interest [29]. CK is necessary for cell division of early embryogenesis, and it is believed to play important roles in anthocyanin accumulation, senescence, and root enlargement in carrot [30-33]. However, CK biosynthesis, inactivation, and response during carrot growth and development remain unclear.

The present work aimed to investigate $\mathrm{CK}$ accumulation during carrot growth and development. Morphological characteristics, anatomical structure, and expression levels of genes involved in CK metabolism and signaling were analyzed and discussed to comprehensively elucidate CK roles in carrot growth and development. The results from our work would provide novel insights into CK-mediated plant growth.

\section{Materials and Methods}

\section{Plant material}

D. carota L. cv. 'Kurodagosun' was selected and cultivated in an artificial chamber at the Nanjing Agricultural University $\left(32^{\circ} 04^{\prime} \mathrm{N}, 118^{\circ} 85^{\prime} \mathrm{E}\right)$. Plants were grown in a mixture of vermiculite and organic soil $(1: 1 ; \mathrm{v} / \mathrm{v})$. The artificial environment was maintained at $25^{\circ} \mathrm{C}$ for $16 \mathrm{~h}$ with a light intensity of $300 \mu \mathrm{mol} \mathrm{m} \mathrm{s}^{-2}$ during daytime followed by $18^{\circ} \mathrm{C}$ for $8 \mathrm{~h}$ in the dark. Carrot plants were sampled at 25 (stage 1), 42 (stage 2), 60 (stage 3), 75 (stage 4), and 90 (stage 5) days after sowing. The developmental stages were classified based on morphological characteristics and dates. For biochemical and molecular analyses, various tissues including roots, petioles, and leaves at different development stages were harvested, frozen, and stored at $-80^{\circ} \mathrm{C}$.

\section{Anatomical structure analysis}

Samples were harvested at $25,42,60,75$, and 90 days after sowing for anatomical structure analysis. We cut fresh samples into small pieces and immediately stored them in phosphate buffer ( $\mathrm{pH} 7.2$ ) with $2.5 \%$ glutaraldehyde. For safranin $\mathrm{O} /$ fast green staining, the slices were first deparaffinized in xylene and dehydrated with ethanol. After dewaxing, we stained the samples with $1 \%$ safranin $\mathrm{O}$ for $2 \mathrm{~h}$ and rinsed off the excess stain with water. Subsequently, slices were dehydrated in a series of ethanol and counterstained with $0.5 \%$ fast green for $15 \mathrm{~s}$. 
Afterward, we washed out excess stain with ethanol and sealed the samples with neutral balsam. The presence of lignin was considered when the tissue sections were stained with red staining under a light microscope and fiber tissues were stained with green staining.

\section{Assay of bioactive CK levels}

Sample grinding was performed in a mortar with $10 \mathrm{~mL}$ of $80 \%$ methanol extraction solution containing $1 \mathrm{mM}$ butylated hydroxytoluene. The mixture was incubated at $4^{\circ} \mathrm{C}$ for $4 \mathrm{~h}$. Afterward, the samples were centrifuged at $3500 \mathrm{~g}$ for $10 \mathrm{~min}$ and the supernatants were passed through a $\mathrm{C}_{18}$ Sep-Pak cartridge (Waters, Milford, MA). Efflux was collected and dried with $\mathrm{N}_{2}$. Residues were dissolved in PBS solution containing 0.1\% (v/v) Tween 20 and $0.1 \%(\mathrm{w} / \mathrm{v})$ gelatin (pH 7.5). To determine endogenous levels of bioactive CKs, including iP and ZT, indirect enzyme-linked immunosorbent assay (ELISA) was carried out as previously described $[34,35]$. The quantification of bioactive CKs by ELISA was performed at the Phytohormones Research Institute, China Agricultural University, Beijing, China.

\section{Total RNA isolation and cDNA synthesis}

The total RNAs of carrot roots, petioles, and leaves were extracted using an RNA extraction kit (Tiangen, Beijing, China) according to the manufacturer's instructions. RNA quality was then assessed with a One-Drop spectrophotometer. Total RNA was incubated at $42^{\circ} \mathrm{C}$ for $2 \mathrm{~min}$ with gDNA Eraser (TaKaRa, Dalian, China) to remove genomic DNA contamination. cDNA synthesis was strictly carried out as described in PrimeScript RT reagent kit (TaKaRa, Dalian, China). Finally, cDNA was diluted 15 -fold, and $2 \mu \mathrm{L}$ of this diluted cDNA was used for quantitative real-time PCR (qRT-PCR) analysis.

\section{Gene expression analysis by qRT-PCR}

To identify the genes involved in CK metabolism and perception, CK-related genes of Arabidopsis were aligned with the sequences in CarrotDB, a genomic and transcriptomic database for carrot (Lab of Apiaceae Plant Genetics and Germplasm Enhancement, http://apiaceae.njau.edu.cn/ carrotdb/index.php) [26]. The gene sequences were listed in Figures A-U in S1 File. The primers of each gene were shown in Tables 1 and 2. qRT-PCR was carried out in a Bio-Rad IQ5 realtime PCR System (Bio-Rad, CA, USA) using TaKaRa SYBR Premix Ex Taq (TaKaRa, Dalian, China). Each PCR mixture comprised a total volume of $20 \mu \mathrm{L}$, which contained $10 \mu \mathrm{L}$ of SYBR Premix Ex Taq, 7.4 $\mu \mathrm{L}$ of sterile deionized water, $2 \mu \mathrm{L}$ of diluted cDNA strand, and $0.4 \mu \mathrm{L}$ of each primer. PCR was conducted following the manufacturer's specifications. The conditions were controlled as follows: $95^{\circ} \mathrm{C}$ for $30 \mathrm{~s}$, followed by 40 cycles at $95^{\circ} \mathrm{C}$ for $5 \mathrm{~s}$ and $60^{\circ} \mathrm{C}$ for $30 \mathrm{~s}$. The raw data were listed in Table A in S1 File. The relative expression levels were normalized against those of the carrot reference gene, DcACTIN [36]. Data from DcIPT3 in carrot leaves at 60 days after sowing were selected as standards for gene expression analysis.

\section{Statistical analysis}

Differences in CK accumulation and gene expression during carrot development were detected by Duncan's multiple-range test at a 0.05 probability level.

\section{Results}

\section{Plant growth analysis}

Roots, petioles, and leaves from 25-, 40-, 60-, 75-, and 90-day-old carrots were sampled (Fig 2). Root and shoot weights, along with root-shoot ratio, were measured to characterize plant 
Table 1. Description of genes involved in cytokinin biosynthesis and inactivation.

\begin{tabular}{|c|c|c|c|}
\hline $\begin{array}{l}\text { Gene } \\
\text { symbol }\end{array}$ & Molecular function & $\begin{array}{l}\text { Homologous locus in } \\
\text { Arabidopsis }\end{array}$ & Primer sequences (forward/reverse) \\
\hline DcIPT3 & Adenylate isopentenyltransferase & AT3G63110 & $\begin{array}{l}\text { GAATGGAATGGTAGATGAGGCAAGACA/ } \\
\text { TCTCTAACTGGCGGCAGGCTAG }\end{array}$ \\
\hline DcIPT5 & Adenylate isopentenyltransferase & AT5G19040 & $\begin{array}{l}\text { TTTGGATGCGACCGAGGCTTT/ } \\
\text { GCCGATAGTGCCGAATCTTCTTC }\end{array}$ \\
\hline DcIPT9 & tRNA isopentenyltransferase & AT5G20040 & $\begin{array}{l}\text { GTAGACTCGCACTTGAACTCGCTAA/ } \\
\text { GGACAACGAAGGCTTGGCAGAA }\end{array}$ \\
\hline DcCYP735A1 & Cytokinin hydroxylase & AT5G38450 & $\begin{array}{l}\text { CTTGTCGGAGACGCACCTGATAA/ } \\
\text { CAATGTGACGCTGATGATACCAATCG }\end{array}$ \\
\hline DcCYP735A2 & Cytokinin hydroxylase & AT1G67110 & $\begin{array}{l}\text { ATATGGAGGATGCGAACACAAGATGG/ } \\
\text { TGTAGAAAGGTGAAAGCGAGAACGAAA }\end{array}$ \\
\hline DcLOG1 & $\begin{array}{l}\text { Cytokinin riboside } 5 \text { '-monophosphate } \\
\text { phosphoribohydrolase }\end{array}$ & AT2G28305 & $\begin{array}{l}\text { CTATTATGATAGCCTGCTTGCCTTGTT/ } \\
\text { AGCCTCTAATGATTGGTCCACTTCC }\end{array}$ \\
\hline DcLOG3 & $\begin{array}{l}\text { Cytokinin riboside } 5^{\prime} \text {-monophosphate } \\
\text { phosphoribohydrolase }\end{array}$ & AT2G37210 & $\begin{array}{l}\text { CAGAGATGGCTAGGCACTCAGATG/ } \\
\text { AAGAGTTGTAGTATCCGTCCACATTGA }\end{array}$ \\
\hline DcLOG8 & $\begin{array}{l}\text { Cytokinin riboside } 5 \text { '-monophosphate } \\
\text { phosphoribohydrolase }\end{array}$ & AT5G11950 & $\begin{array}{l}\text { GATTGACTTGGTGTATGGTGGTGGTAG/ } \\
\text { TTACATCTCCAACAGTCTCGCCAGA }\end{array}$ \\
\hline$D c C Y X 1$ & Cytokinin dehydrogenase & AT2G41510 & $\begin{array}{l}\text { GCCACATTACCACAAGCAAGAAGAGT/ } \\
\text { TCCAGGAGCAAGAAGTGCCAGAG }\end{array}$ \\
\hline$D c C Y X 7$ & Cytokinin dehydrogenase & AT5G21482 & $\begin{array}{l}\text { TCTGTACTGTCTGGAGGTCGCATT/ } \\
\text { CCGTTAGCTCTAGCTTGTTGTTCGT }\end{array}$ \\
\hline
\end{tabular}

doi:10.1371/journal.pone.0134166.t001

Table 2. Description of genes related to cytokinin perception.

\begin{tabular}{|c|c|c|c|}
\hline $\begin{array}{l}\text { Gene } \\
\text { symbol }\end{array}$ & Molecular function & $\begin{array}{l}\text { Homologous locus in } \\
\text { Arabidopsis }\end{array}$ & Primer sequences (forward/reverse) \\
\hline DcHK2 & Histidine kinase & AT5G35750 & $\begin{array}{l}\text { TGAAGTCTCCACAGTACCGTCCAA/ } \\
\text { AGAAGCATACGCAGAATCCAGAGTC }\end{array}$ \\
\hline DcHK3 & Histidine kinase & AT1G27320 & $\begin{array}{l}\text { GATGCTAATTGGCGATCCTGGAAGAT/ } \\
\text { ACAAGATGGACCGTTACGAAGATATGC }\end{array}$ \\
\hline DcHP1a & $\begin{array}{l}\text { Histidine-containing } \\
\text { phosphotransfer protein }\end{array}$ & AT3G21510 & $\begin{array}{l}\text { AGCATTGGAGCACAAAGAGTTCAGA/ } \\
\text { ATCCACCAGCAGCCACAAGTTG }\end{array}$ \\
\hline DcHP1b & $\begin{array}{l}\text { Histidine-containing } \\
\text { phosphotransfer protein }\end{array}$ & AT3G21510 & TTCGTGGCTTCTGCGATGAACA/ CTTCCACAATCTGCCGCTCCAA \\
\hline DcHP3 & $\begin{array}{l}\text { Histidine-containing } \\
\text { phosphotransfer protein }\end{array}$ & AT5G39340 & $\begin{array}{l}\text { CGATGCCTGTGTTCACCAATTCAAG/ } \\
\text { CATCTCAAGCACCCTTCCAAGTTCT }\end{array}$ \\
\hline$D c R R-B 1$ & $\begin{array}{l}\text { Two-component response } \\
\text { regulator }\end{array}$ & AT4G16110 & $\begin{array}{l}\text { CACCGCAGAGGAACCGATGATG/ } \\
\text { AGCTCCACCGACCAGACTACAC }\end{array}$ \\
\hline$D c R R-B 2$ & $\begin{array}{l}\text { Two-component response } \\
\text { regulator }\end{array}$ & AT4G16110 & $\begin{array}{l}\text { CAAGCAGCCCTAGTTCAACAAAGC/ } \\
\text { GCATATTCCTGTGTCCATTCTCTTCCA }\end{array}$ \\
\hline$D c R R-B 3$ & $\begin{array}{l}\text { Two-component response } \\
\text { regulator }\end{array}$ & AT1G67710 & $\begin{array}{l}\text { GAAGGCAACCAGCAGTTCAGGAG/ } \\
\text { GGTCGAGATCAGGCAATGACAGATG }\end{array}$ \\
\hline$D c R R-B 4$ & $\begin{array}{l}\text { Two-component response } \\
\text { regulator }\end{array}$ & AT2G25180 & $\begin{array}{l}\text { TTCAATACTGCTCAGATGCCTCCTAAC/ } \\
\text { CCGCCTTGGTGTTCTCCTCTTG }\end{array}$ \\
\hline$D c R R-A 1$ & $\begin{array}{l}\text { Two-component response } \\
\text { regulator }\end{array}$ & AT3G57040 & $\begin{array}{l}\text { GCAGAACAGGAGGAAGTATCATCACA/ } \\
\text { TTCTCTTCGTGTTATTGCCGTCATCT }\end{array}$ \\
\hline$D c R R-A 2$ & $\begin{array}{l}\text { Two-component response } \\
\text { regulator }\end{array}$ & AT3G57040 & $\begin{array}{l}\text { GATGTTTAGAGGAAGGAGCAGATGAGT/ } \\
\text { TGCTTCTTGCTGTAATGACTGAATCAC }\end{array}$ \\
\hline
\end{tabular}

doi:10.1371/journal.pone.0134166.t002 

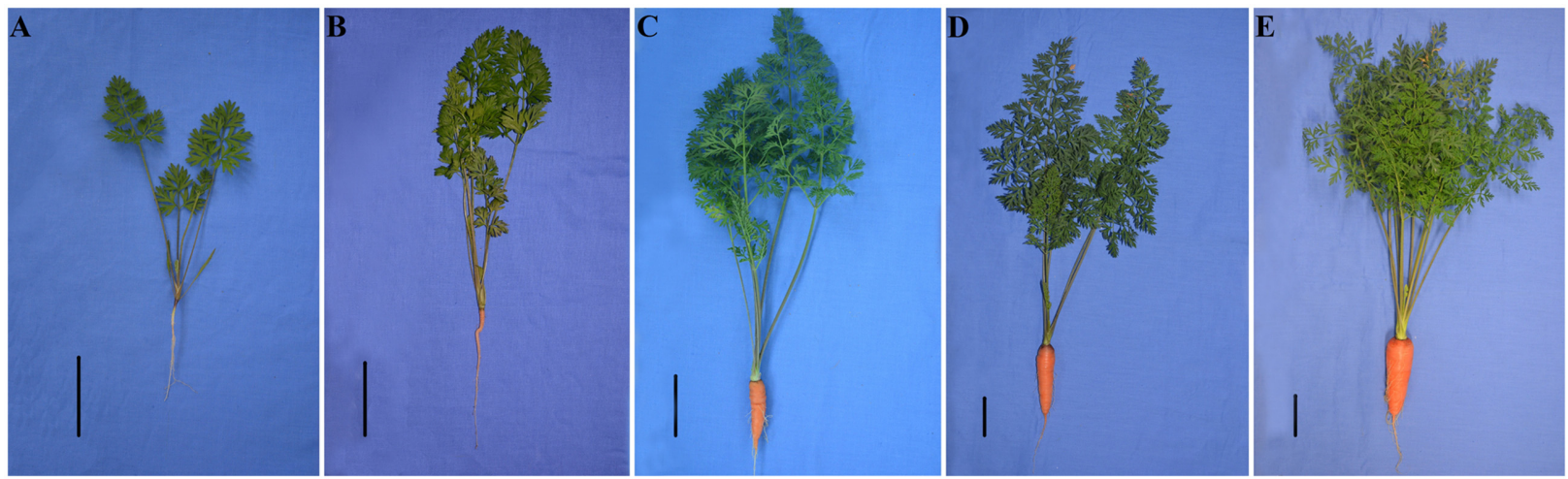

Fig 2. Growth status of carrots from five different developmental stages. A: Stage 1, 25-day-old. B: Stage 2, 40-day-old. C: Stage 3, 60-day-old. D: Stage 4, 75-day-old. E: Stage 5, 90-day-old. Black lines in the lower left corner of each plant represent $5 \mathrm{~cm}$ in that pixel.

doi:10.1371/journal.pone.0134166.g002

growth during carrot development. The fresh weight of shoots was way above that of roots at stage 1. After 15 days, an orange color first appeared on the root surface. Shoot and root weights evidently increased at stage 2 , whereas the root-shoot ratio was not significantly changed. The roots kept on enlarging, and root weight was approximately equal to shoot weight at the third stage. Finally, shoot weight was far less than that of root weight, and this trend was maintained at the final stage (Fig 3).

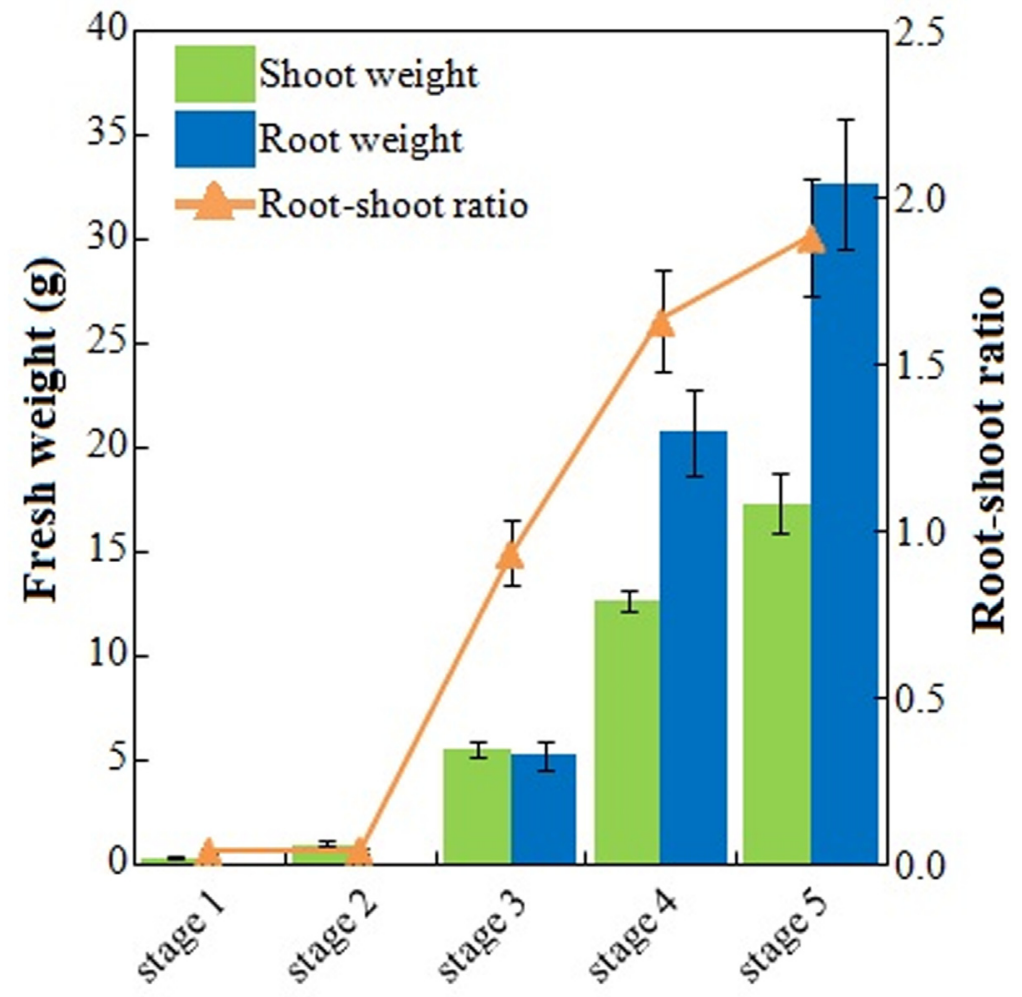

Fig 3. Characterization of root weight and shoot weight during carrot growth and development. Error bars represent standard deviation among three independent replicates. Data indicate mean \pm SD of three replicates.

doi:10.1371/journal.pone.0134166.g003 


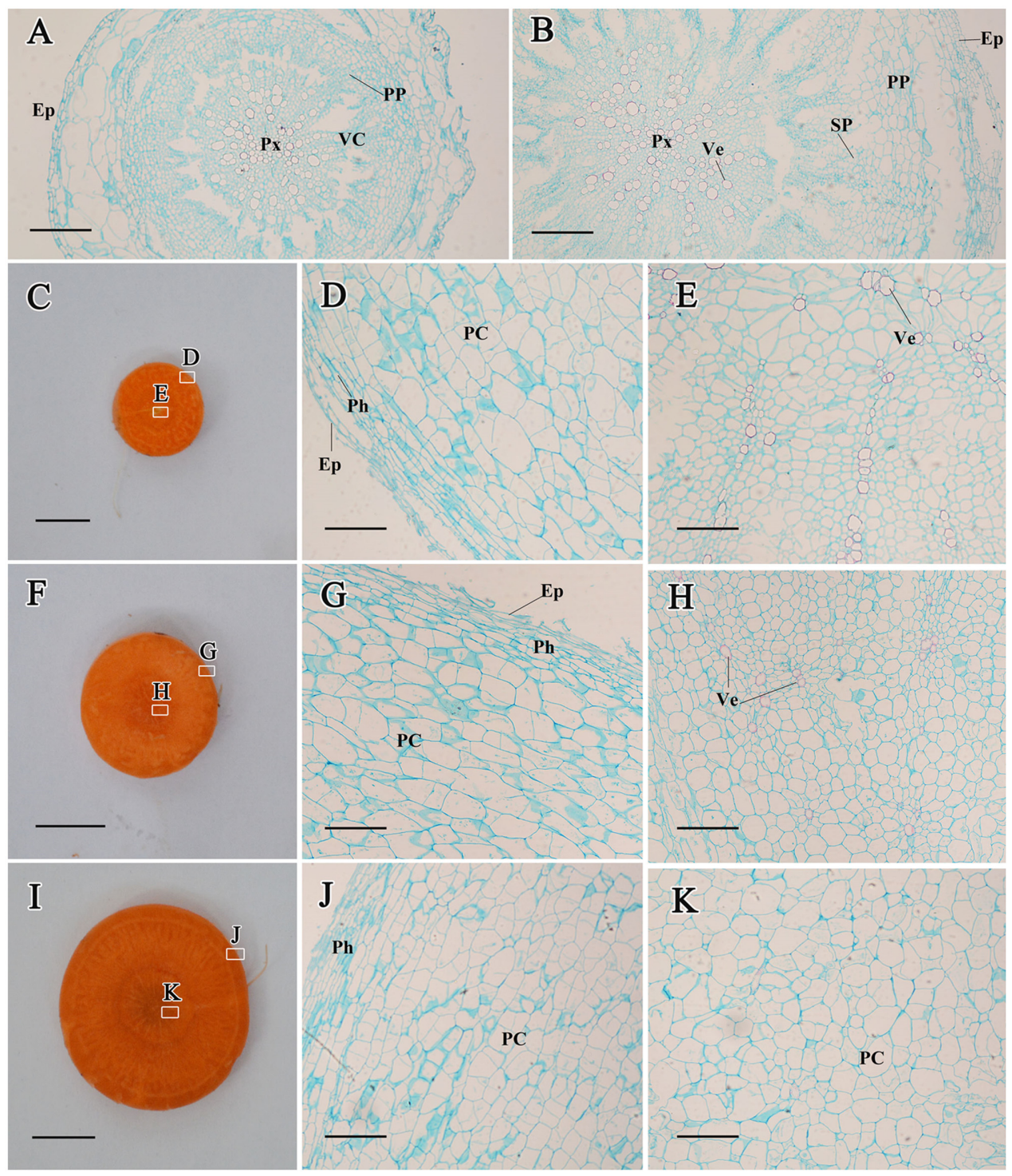

Fig 4. Structural changes in the carrot roots from stage 1 (A), stage 2 (B), stage 3 (C, D, and E), stage 4 $(\mathbf{F}, \mathbf{G}$, and $\mathbf{H})$, and stage $5(\mathrm{I}, \mathbf{J}$, and $\mathrm{K})$. Epidermis (Ep), parenchymalcell (PC), phellogen (Ph), primary phloem (PP), protoxylem (Px), secondary phloem (SP), vascularcambium (VC), and vessel (Ve) are marked in the Figure. Scale bars in A, B, D, E, G, H, J, and K are $100 \mu \mathrm{m}$ in length, whereas scale bars in C, F, and I are $1 \mathrm{~cm}$ in length.

doi:10.1371/journal.pone.0134166.g004

\section{Anatomical structure in the roots, petioles, and leaves}

In the roots. At stage 1, protoxylem ( $\mathrm{Px})$, vascularcambium $(\mathrm{VC})$, primary phloem $(\mathrm{PP})$, and epidermis were observed in the basic root structure, and no significant thickness was detected at this stage (Fig 4A). After 15 days, the secondary phloem (SP) region appeared between VC and PP (Fig 4B). Subsequently, parenchymalcells became larger, and the roots continued to enlarge (Fig 4C, 4F and 4I).

In the petioles. The petiole diameter increased over the process of carrot growth (Fig 5). Interestingly, the number of vascular bundles in the petioles also significantly increased, suggesting a constant thickness during this process. 


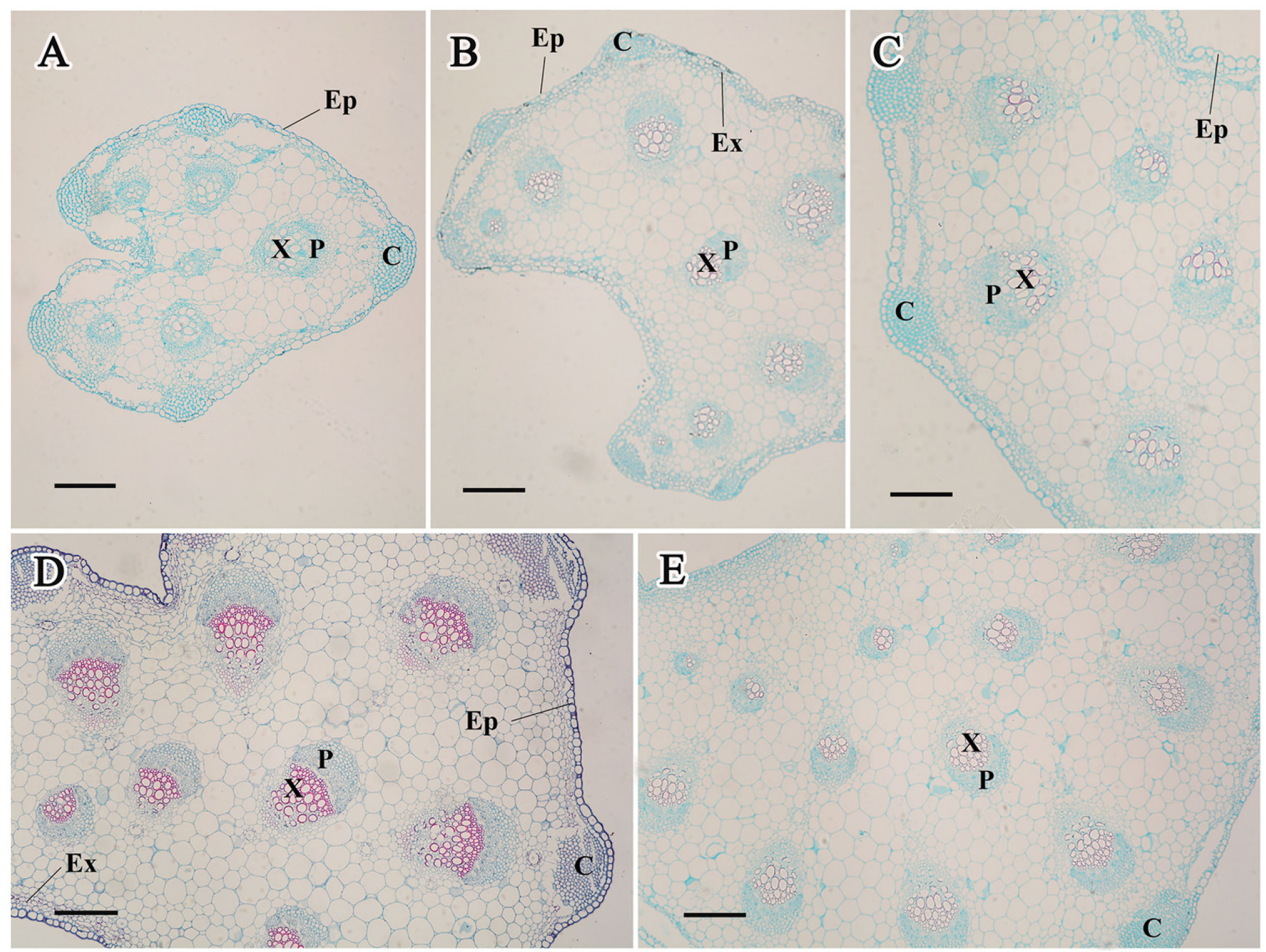

Fig 5. Structural changes in the carrot petioles from stage 1 (A), stage 2 (B), stage 3 (C), stage 4 (D), and stage $5(E)$. Collenchyma (C), epidermis (Ep), exodermis (Ex), phloem (P), and xylem (X) are marked in the Figure. Scale bars in A, B, C, D, and E are $100 \mu \mathrm{m}$ in length.

doi:10.1371/journal.pone.0134166.g005

In the leaves. Palisade and spongy tissues are the main tissue types in mesophyll, which allow plant photosynthesis and gas exchange. At stages 1 and 2, the numbers of palisade and spongy cells were limited (Fig 6A and 6B). The palisade cells in the leaf obviously increased, and the ratio of palisade tissue to spongy tissue was high (Fig 6C, 6D and 6E).

\section{Changes in bioactive CKs}

The levels of bioactive CKs (iP and ZT) in roots, petioles, and leaves at different developmental stages were measured (Fig 7). In the roots, both iP and ZT levels were highest at stage 2 but suddenly decreased at stage 3 . In the petioles, iP and ZT levels showed a similar pattern, which had the highest level at stage 4 . The iP content in the leaves showed a trend similar to that in the petioles, whereas ZT was maintained at a relatively stable level during carrot growth. For each plant, both iP and ZT contents in the roots were lower than those in the petioles and leaves, except at stage 2 . In addition, the ZT content during all stages was greater than the iP content.

\section{Expression profiles of genes involved in CK biosynthesis and inactivation}

DcIPT3, DcIPT5, DcIPT9, DcCYP735A1, DcCYP735A2, DcLOG1, DcLOG3, DcLOG8, DcCYX1, and $D c C Y X 7$ were involved in $\mathrm{CK}$ biosynthesis and degradation, as revealed by CarrotDB (Table 1). The transcript levels of these selected genes were evidently altered in response to carrot growth and development (Fig 8). 


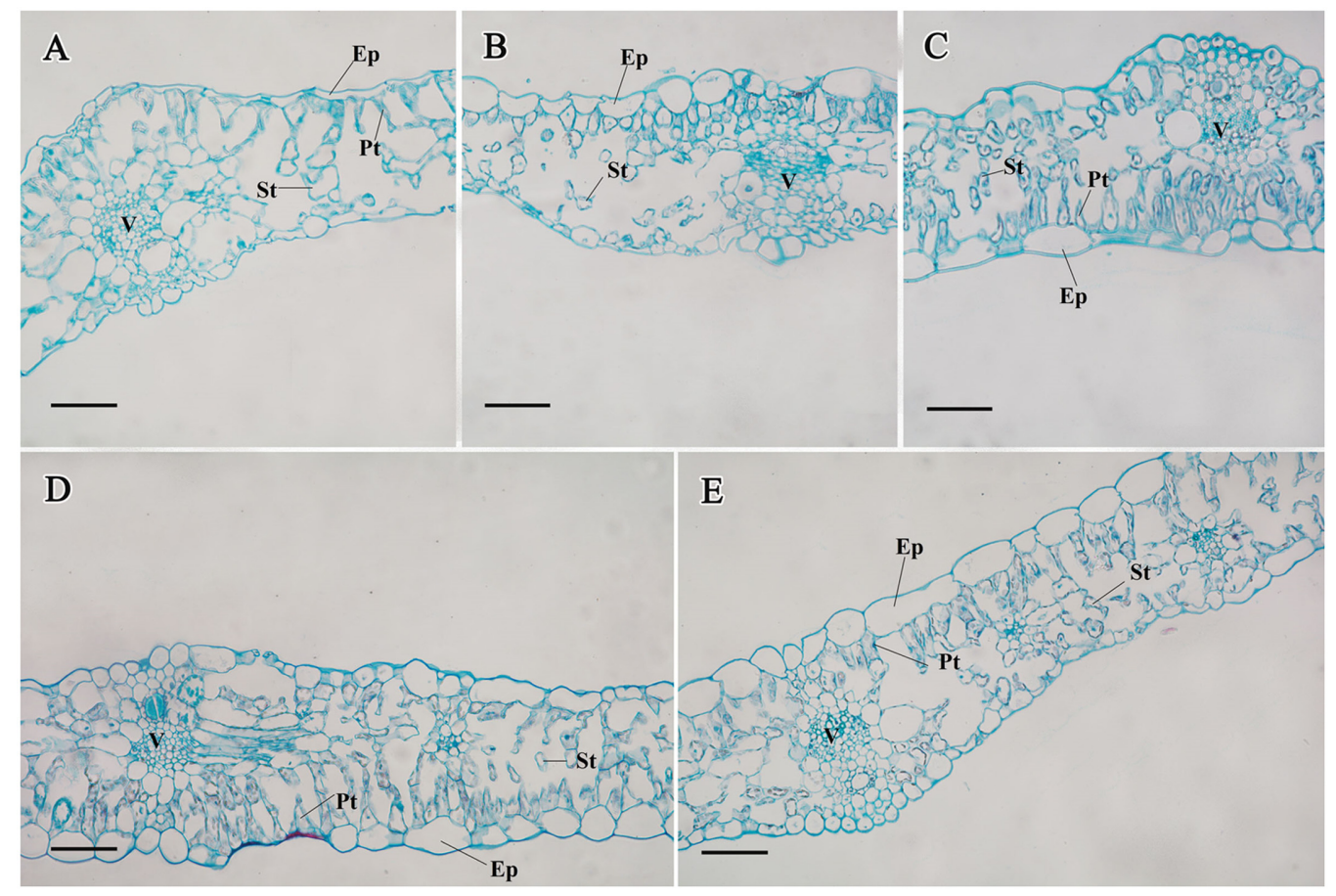

Fig 6. Structural changes in the carrot leaves from stage 1 (A), stage 2 (B), stage 3 (C), stage 4 (D), and stage 5 (E). Epidermis (Ep), palisade tissue $(\mathrm{Pt})$, spongy tissue $(\mathrm{St})$, and vascular tissue $(\mathrm{V})$ are marked in the Figure. Scale bars in $\mathrm{A}, \mathrm{B}, \mathrm{C}, \mathrm{D}$, and $\mathrm{E}$ are $100 \mu \mathrm{m}$ in length.

doi:10.1371/journal.pone.0134166.g006

In the roots, two gene copies of IPT, namely, DcIPT3 and DcIPT5, showed higher expression at the first stage (stage 1) and relatively low expression at other stages. By contrast, an opposite trend was detected in the DcIPT9 gene that encodes tRNA-IPT. DcCYP735A1 showed the lowest expression at stages 2 and 3, whereas DcCYP735A2 that encodes CK hydroxylase was highly expressed at stage 2. Transcript levels of DcLOG1 and DcLOG8 were higher at the first stage, whereas DcLOG3 displayed high expression at the third stage and consistently low expression
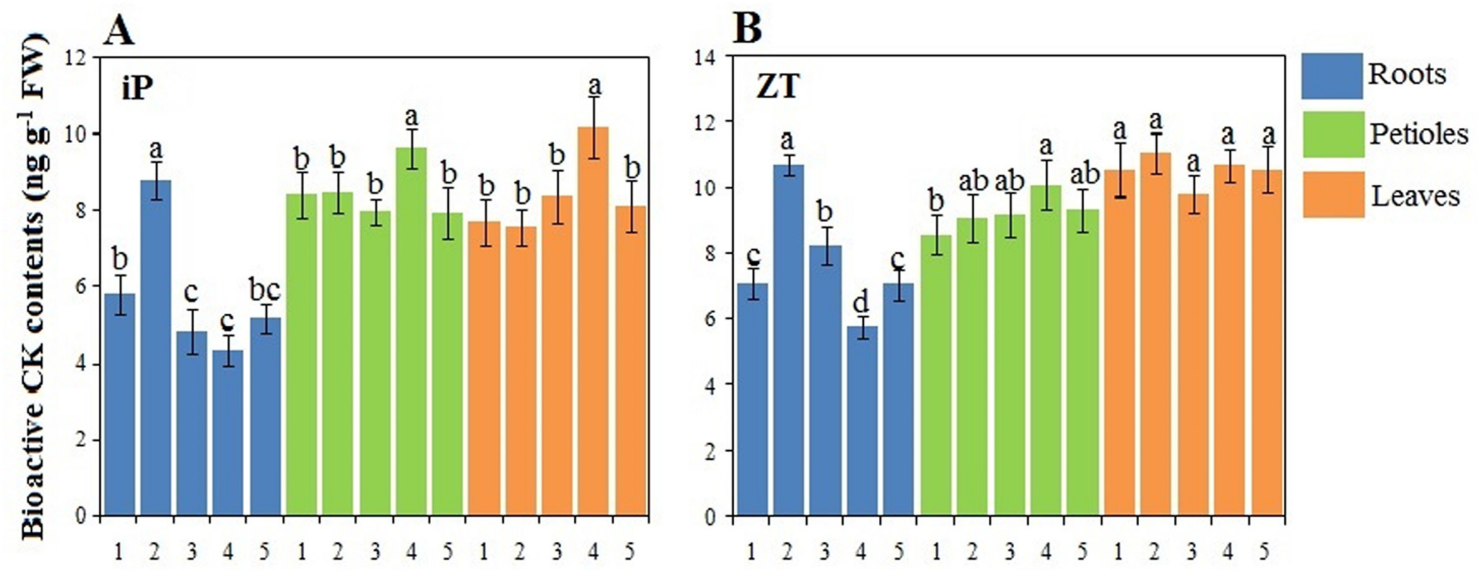

Developmental stages

Fig 7. Bioactive CK levels in different tissues during carrot growth and development. Error bars represent standard deviation among three independent replicates. Data indicate mean $\pm \mathrm{SD}$ of three replicates. Different lowercase letters indicate significant differences at $P<0.05$. 
at other stages. In the petioles, the expression profiles of DcIPT3, DcIPT5, and DcIPT9 differed from one another during plant growth. The mRNA levels of DcCYP735A1 and DcCYP735A2 were the highest at the third stage. A large amount of DcLOG1 transcript was detected at stage 2, whereas DcLOG3 was higher at the last stage. $D c C Y X 1$ showed high expression at the last stage, but low expression at stages 2 and 4 . In the leaves, DcIPT9 showed high expression at stages 1,2 and 5, and low expression at other stages. Conversely, DcIPT5 was highly expressed at stages 3 and 4. Expression of DcIPT3 and DcCYP735A1 in the leaves was similar to that in the petioles. High transcript levels of DcCYP735A2 and DcLOG1 were detected at stage 2, whereas $D c C Y X 7$ was highly expressed at the last stage.

Interestingly, some analyzed genes were expressed in a tissue-specific manner. For instance, mRNA abundances of DcIPT3 and DcCYX7 were higher in the leaves than in the roots and petioles, whereas an opposite trend was detected in DcCYX1 expression (Fig 8).

\section{Expression of CK-responsive genes during carrot growth and development}

CK signal perception and transduction are essential components in the CK network. Thus, the dynamics of $\mathrm{CK}$ receptors should be identified to fully understand $\mathrm{CK}$ roles during carrot growth. The expression of genes involved in CK response, namely, DcHK2, DcHK3, DcHP1a, $D c H P 1 b, D c H P 3, D c R R-B 1, D c R R-B 2, D c R R-B 3, D c R R-B 4, D c R R-A 1$, and $D c R R-A 2$, were all different from one another (Fig 9).

In the roots, mRNA abundance of $D c H P 1 b$ and $D c R R-A 1$ showed a pattern similar to that of iP accumulation in the roots. DcHP3 expression remained relatively stable during plant growth. $D c R R-B 2$ and $D c R R-B 4$ exhibited high expression at stages 1 and 2, and low expression at the last stage. $D c H K 2$ and $D c H P 1 a$ were highly expressed at stage 2 , whereas high transcript levels of $D c H K 3$ and $D c R R-B 1$ were detected at the third stage. Transcription of $D c R R-B 3$ decreased over the process of root development. The expression of $D c R R-A 2$ at stages 1,2 and 5 was higher than at other stages. In the petioles, high transcript levels of $D c H K 2, D c H K 3$, and $D c R R-B 1$ were detected at the third stage. Expression of $D c H P 1 b$ showed a pattern opposite to those of iP and ZT. Transcription of $D c R R-B 2$ increased over the first three stages, and slightly changed at the last two stages. By contrast, the mRNA level of $D c R R-A 1$ was higher at the first two stages and relatively low at the last three stages. $D c R R-A 2$ was the only gene that exhibited decreased expression over the developmental stages. In the leaves, mRNA abundance of $D c H K 2$ was higher at the first two stages. Transcription of $D c H P 3$ remained relatively low at the first three stages. Conversely, $D c H P 1 a$ and $D c R R-B 4$ were highly expressed at the first three stages. $D c R R-B 1$ showed high expression at stage 1 and consistently low expression at other stages. $D c R R-B 3$ was highly expressed at the third stage, whereas expression of $D c R R-A 1$ was lowest at this stage. $D c R R-A 2$ was the only gene that was highly expressed at the last stage.

\section{Discussion}

Plant growth and development is under tight control of both environmental signals and intrinsic cues [37]. Hormones are a class of molecules that can serve as important signals and lead to the induction or repression of the target genes, thereby regulating plant growth $[1,38,39]$. Among them, CKs can promote cell division in plant roots and shoots, which is mainly achieved by stimulating the production of proteins needed for mitosis [11,40,41]. Thus, a better understanding of CK accumulation and its potential roles during plant growth is of vital importance.

Carrot is a vegetable crop with high nutritional value. 'Kurodagosun' is a carrot variety with high and stable production worldwide and has been extensively used in molecular and genetic studies $[27,42]$. 'Kurodagosun' undergoes evident size change during plant growth, which may 

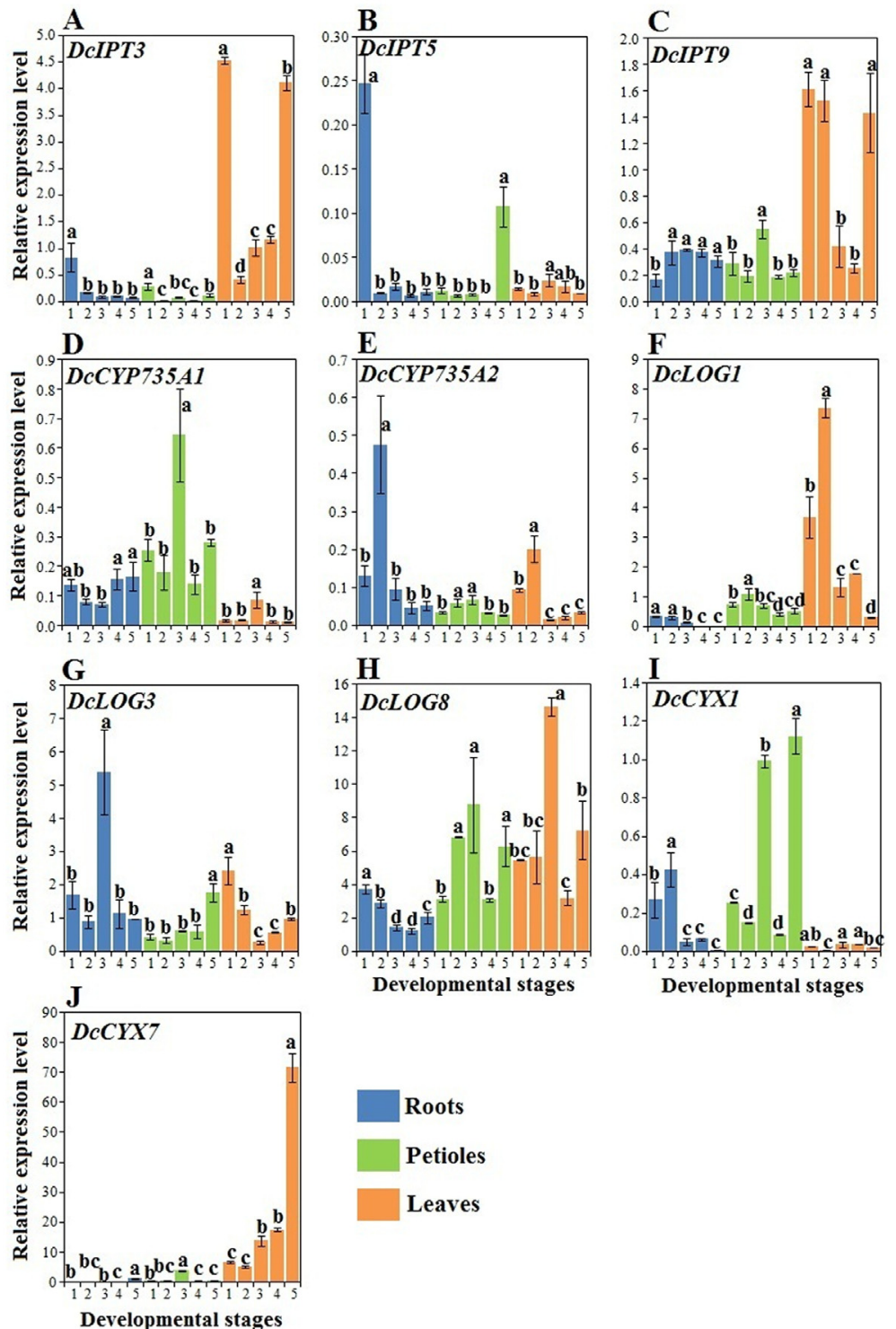

Developmental stages

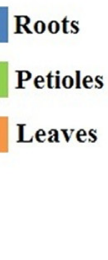

Fig 8. qRT-PCR analysis of genes involved in CK biosynthesis and inactivation among different tissues during carrot growth and development. Error bars represent standard deviation among three independent replicates. Data indicate mean \pm SD of three replicates. Different lowercase letters indicate significant differences at $P<0.05$.

doi:10.1371/journal.pone.0134166.g008

require the involvement of hormones. However, only limited information regarding CK has been documented in carrot. The results from the current study would substantially improve the understanding of $\mathrm{CK}$ accumulation and potential during carrot growth.

As a whole, CK levels differed from different developmental stages and various tissues, indicating that CKs may regulate plant growth in a stage-dependent and tissue-specific manner $[10,43]$. CKs are assumed to be synthesized not only in the meristem of the roots but also in the shoots [44]. Once CK has been produced, it is translocated to other regions of the plant where continuous growth occurs [45]. CKs are necessary for cell division and may play important roles in vascular development $[46,47]$. In the present work, we found that CKs were present in all tissues, which may provide constant support for structure formation and development. Our 

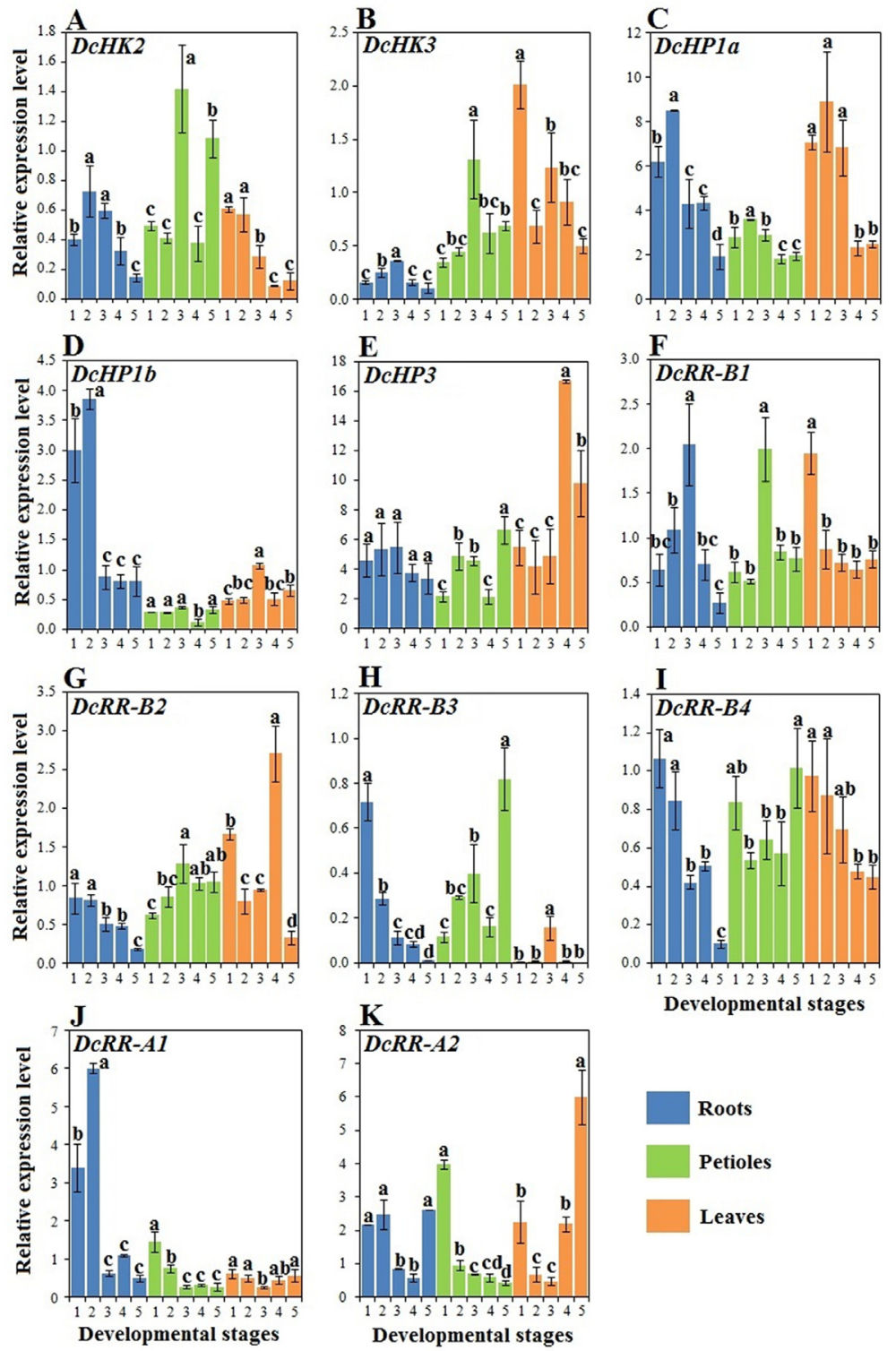

Developmental stages

Fig 9. qRT-PCR analysis of genes involved in CK perception among different tissues during carrot growth and development. Error bars represent standard deviation among three independent replicates. Data indicate mean \pm SD of three replicates. Different lowercase letters indicate significant differences at $P$ $<0.05$.

doi:10.1371/journal.pone.0134166.g009

results also showed that higher levels of iP and ZT occurred at the second stage in the roots. Anatomical structure analysis revealed obvious enlargement at this stage (Fig 4). These results led us to hypothesize that the second stage was crucial to root growth, and CKs may play important roles at this stage.

All analyzed genes were expressed among different tissues, supporting the idea that various tissues can produce CKs [10]. The expression of most genes did not follow a pattern similar to that of $\mathrm{iP}$ and $\mathrm{ZT}$ accumulation. However, these genes are believed to be essentially required for CK accumulation. For example, transcription of DcCYP735A2 was higher at stage 2 in the roots, which may largely contribute to higher levels of CKs at this stage. Furthermore, CK 
biosynthesis is regulated not only by transcriptional mechanisms but also by post-translational events [48,49]. Some tissue-specific genes, such as DcIPT3, DcCYP735A1, and DcCYX7, were also identified. All these results suggested that a complex regulatory network for CK metabolism in carrot.

In comparison with biosynthetic routes, $\mathrm{CK}$ signal perception and transduction are equally important [50-52]. In Arabidopsis, the transcriptional levels of $A R R-A$ and $A H P$ can be rapidly induced by changes in CK levels, whereas those of others cannot [53,54]. Similarly, DcHP1b and $D c R R-A 1$ showed a pattern similar to that of CK accumulation in roots, whereas transcription of genes encoding type-B RRs was not well correlated with CK accumulation. However, such genes are still integral to the whole pathway. Collectively, the genes encoding the receptors are important to CK signal transduction and normal plant growth and development [52].

\section{Conclusions}

As a carrot grows, significant alterations occur in its morphological and anatomical structure, $\mathrm{CK}$ accumulation, and gene expression. CK plays important roles in carrot plant growth, and it may be particularly crucial to root enlargement at the second stage. CK biosynthesis is a complex regulatory network that needs the involvement of many genes. Genes involved in CK perception and transduction are also indispensable to normal plant growth. The current work has substantially improved the understanding of CK accumulation and its potential roles during carrot development.

\section{Supporting Information}

S1 File. Relevant data underlying the findings described in the manuscript. Figures A-U. Nucleotide acid and deduced amino sequences of CK-related genes. Table A. Raw Cq (quantification cycle) values of genes in different tissues during carrot growth and development. (DOCX)

\section{Author Contributions}

Conceived and designed the experiments: ASX GLW. Performed the experiments: GLW SS XJW FW. Analyzed the data: GLW. Contributed reagents/materials/analysis tools: ASX. Wrote the paper: GLW. Revised the paper: GLW GMX ASX.

\section{References}

1. Ordaz-Ortiz JJ, Foukaraki S, Terry LA (2015) Assessing temporal flux of plant hormones in stored processing potatoes using high definition accurate mass spectrometry. Horticulture Research 2: 15002.

2. Wolters $\mathrm{H}$, Jurgens $\mathrm{G}$ (2009) Survival of the flexible: hormonal growth control and adaptation in plant development. Nature Reviews Genetics 10: 305-317. doi: 10.1038/nrg2558 PMID: 19360022

3. Bartrina I, Otto E, Strnad M, Werner T, Schmülling T (2011) Cytokinin regulates the activity of reproductive meristems, flower organ size, ovule formation, and thus seed yield in Arabidopsis thaliana. Plant Cell 23: 69-80. doi: 10.1105/tpc.110.079079 PMID: 21224426

4. Wang Y, Li L, Ye T, Zhao S, Liu Z, Feng YQ, et al. (2011) Cytokinin antagonizes ABA suppression to seed germination of Arabidopsis by downregulating ABI5 expression. Plant Journal 68: 249-261. doi: 10.1111/j.1365-313X.2011.04683.x PMID: 21699589

5. Wingler A, von Schaewen A, Leegood RC, Lea PJ, Paul Quick W (1998) Regulation of leaf senescence by cytokinin, sugars, and light: effects on NADH-dependent hydroxypyruvate reductase. Plant Physiology 116: 329-335.

6. El-Showk S, Ruonala R, Helariutta Y (2013) Crossing paths: cytokinin signalling and crosstalk. Development 140: 1373-1383. doi: 10.1242/dev.086371 PMID: 23482484 
7. Frébort I, Kowalska M, Hluska T, Frébortová J, Galuszka P (2011) Evolution of cytokinin biosynthesis and degradation. Journal of Experimental Botany 62: 2431-2452. doi: 10.1093/jxb/err004 PMID: 21321050

8. Kieber JJ, Schaller GE (2010) The perception of cytokinin: astory 50 years in the making. Plant Physiology 154: 487-492. doi: 10.1104/pp.110.161596 PMID: 20921170

9. Song J, Jiang L, Jameson $\mathrm{P}$ (2012) Co-ordinate regulation of cytokinin gene family members during flag leaf and reproductive development in wheat. BMC Plant Biology 12: 78. doi: 10.1186/1471-222912-78 PMID: 22672647

10. Miyawaki K, Kakimoto T, Matsumoto-Kitano M (2004) Expression of cytokinin biosynthetic isopentenyltransferase genes in Arabidopsis: tissue specificity and regulation by auxin, cytokinin and nitrate. Plant Journal 37: 128-138. PMID: 14675438

11. Takei K, Yamaya T, Sakakibara H (2004) Arabidopsis CYP735A1 and CYP735A2 encode cytokinin hydroxylases that catalyze the biosynthesis of trans-zeatin. Journal of Biological Chemistry 279: 41866-41872. PMID: 15280363

12. Kuroha $T$, Tokunaga $H$, Kojima M, Ueda N, Ishida T, Nagawa S, et al. (2009) Functional analyses of LONELYGUY cytokinin-activating enzymes reveal the importance of the direct activation pathway in Arabidopsis. Plant Cell 21: 3152-3169. doi: 10.1105/tpc.109.068676 PMID: 19837870

13. Veach YK, Martin RC, Mok DWS, Malbeck J, Vankova R, Mok MC (2003) O-glucosylation of cis-zeatin in maize. Characterization of genes, enzymes, and endogenous cytokinins. Plant Physiology 131: 1374-1380. PMID: 12644686

14. Houba-Hérin N, Pethe C, D’Alayer J, Laloue M (1999) Cytokinin oxidase from Zea mays: purification, cDNA cloning and expression in moss protoplasts. Plant Journal 17: 615-626. PMID: 10230061

15. Kakimoto T (1996) CKI1, a histidine kinase homolog implicated in cytokinin signal transduction. Science 274: 982-985. PMID: 8875940

16. Heyl A, Schmülling T (2003) Cytokinin signal perception and transduction. Current Opinion in Plant Biology 6: 480-488. PMID: 12972049

17. Cheng CY, Kieber J (2014) Cytokinin signaling in plants. In: Howell SH, editor. Molecular Biology: Springer New York. pp. 269-289.

18. Pekárová B, Klumpler T, Třísková O, Horák J, Jansen S, Dopitová R, et al. (2011) Structure and binding specificity of the receiver domain of sensor histidine kinase CKI1 from Arabidopsis thaliana. Plant Journal 67: 827-839. doi: 10.1111/j.1365-313X.2011.04637.x PMID: 21569135

19. Hutchison CE, Li J, Argueso C, Gonzalez M, Lee E, Lewis MW, et al. (2006) The Arabidopsis histidine phosphotransfer proteins are redundant positive regulators of cytokinin signaling. Plant Cell 18: 30733087. PMID: 17122069

20. Jeon J, Kim J (2013) Arabidopsis response regulator1 and Arabidopsis histidine phosphotransfer protein2 (AHP2), AHP3, and AHP5 function in cold signaling. Plant Physiology 161: 408-424. doi: 10. 1104/pp.112.207621 PMID: 23124324

21. Werner T, Motyka V, Laucou V, Smets R, Van Onckelen H, Schmülling T (2003) Cytokinin-deficient transgenic Arabidopsis plants show multiple developmental alterations indicating opposite functions of cytokinins in the regulation of shoot and root meristem activity. Plant Cell 15: 2532-2550. PMID: 14555694

22. Werner T, Nehnevajova E, Köllmer I, Novák O, Strnad M, Krämer U, et al. (2010) Root-specific reduction of cytokinin causes enhanced root growth, drought tolerance, and leaf mineral enrichment in Arabidopsis and Tobacco. Plant Cell 22: 3905-3920. doi: 10.1105/tpc.109.072694 PMID: 21148816

23. Ashikari M, Sakakibara H, Lin S, Yamamoto T, Takashi T, Nishimura A, et al. (2005) Cytokinin oxidase regulates rice grain production. Science 309: 741-745. PMID: 15976269

24. Luby CH, Maeda HA, Goldman IL (2014) Genetic and phenological variation of tocochromanol (vitamin E) content in wild (Daucus carota L. var. carota) and domesticated carrot (D. carota L. var. sativa). Horticulture Research 1: 14015.

25. Xu ZS, Huang Y, Wang F, Song X, Wang GL, Xiong AS (2014) Transcript profiling of structural genes involved in cyanidin-based anthocyanin biosynthesis between purple and non-purple carrot (Daucus carota L.) cultivars reveals distinct patterns. BMC Plant Biology 14: 262. doi: 10.1186/s12870-0140262-y PMID: 25269413

26. Xu ZS, Tan HW, Wang F, Hou XL, Xiong AS (2014) CarrotDB: a genomic and transcriptomic database for carrot. Database 2014: bau096. doi: 10.1093/database/bau096 PMID: 25267795

27. Wang GL, Xu ZS, Wang F, Li MY, Tan GF, Xiong AS (2015) Regulation of ascorbic acid biosynthesis and recycling during root development in carrot (Daucus carota L.). Plant Physiology and Biochemistry 94: 10-18. doi: 10.1016/j.plaphy.2015.04.014 PMID: 25956452 
28. Moreno JC, Pizarro L, Fuentes P, Handford M, Cifuentes V, Stange C (2013) Levels of lycopene $\beta$ cyclase 1 modulate carotenoid gene expression and accumulation in Daucus carota. PLoS ONE 8: e58144. doi: 10.1371/journal.pone.0058144 PMID: 23555569

29. Wang GL, Jia XL, Xu ZS, Wang F, Xiong AS (2015) Sequencing, assembly, annotation, and gene expression: novel insights into the hormonal control of carrot root development revealed by a highthroughput transcriptome. Molecular Genetics and Genomics doi: 10.1007/s00438-015-0999-5

30. Tokuji Y, Kuriyama K (2003) Involvement of gibberellin and cytokinin in the formation of embryogenic cell clumps in carrot (Daucus carota). Journal of Plant Physiology 160: 133-141. PMID: 12685029

31. Chen CM, Ertl JR, Leisner SM, Chang CC (1985) Localization of cytokinin biosynthetic sites in pea plants and carrot roots. Plant Physiology 78: 510-513. PMID: 16664274

32. Deikman J, Hammer PE (1995) Induction of anthocyanin accumulation by cytokinins in Arabidopsis thaliana. Plant Physiology 108: 47-57. PMID: 12228453

33. Carimi F, Terzi M, De Michele R, Zottini M, Lo Schiavo F (2004) High levels of the cytokinin BAP induce PCD by accelerating senescence. Plant Science 166: 963-969.

34. Yang YM, Xu CN, Wang BM, Jia JZ (2001) Effects of plant growth regulators on secondary wall thickening of cotton fibres. Plant Growth Regulation 35: 233-237.

35. Teng N, Wang J, Chen T, Wu X, Wang Y, Lin J (2006) Elevated $\mathrm{CO}_{2}$ induces physiological, biochemical and structural changes in leaves of Arabidopsis thaliana. New Phytologist 172: 92-103. PMID: 16945092

36. Tian C, Jiang Q, Wang F, Wang GL, Xu ZS, Xiong AS (2015) Selection of suitable reference genes for qPCR normalization under abiotic stresses and hormone stimuli in carrot leaves. PLoS ONE 10: e0117569. doi: 10.1371/journal.pone.0117569 PMID: 25658122

37. Sieberer T, Hauser MT, Seifert GJ, Luschnig C (2003) PROPORZ1, a putative Arabidopsis transcriptional adaptor protein, mediates auxin and cytokinin signals in the control of cell proliferation. Current Biology 13: 837-842. PMID: 12747832

38. Rocha F, Papini-Terzi F, Nishiyama M, Vencio R, Vicentini R, Duarte R, et al. (2007) Signal transduction-related responses to phytohormones and environmental challenges in sugarcane. BMC Genomics 8: 71. PMID: 17355627

39. Gapper NE, Giovannoni JJ, Watkins CB (2014) Understanding development and ripening of fruit crops in an 'omics' era. Horticulture Research 1: 14034.

40. Zhang K, Diederich L, John PCL (2005) The cytokinin requirement for cell division in cultured Nicotiana plumbaginifolia cells can be satisfied by yeast $\mathrm{Cdc} 25$ protein tyrosine phosphatase. Implications for mechanisms of cytokinin response and plant development. Plant Physiology 137: 308-316. PMID: 15618425

41. Zhang W, Swarup R, Bennett M, Schaller GE, Kieber Joseph J (2013) Cytokinin induces cell division in the quiescent center of the Arabidopsis root apical meristem. Current Biology 23: 1979-1989. doi: 10. 1016/j.cub.2013.08.008 PMID: 24120642

42. Huang Y, Li MY, Wang F, Xu ZS, Huang W, Wang GL, et al. (2014) Heat shock factors in carrot: genome-wide identification, classification, and expression profiles response to abiotic stress. Molecular Biology Reports 42: 893-905. doi: 10.1007/s11033-014-3826-x PMID: 25403331

43. Le DT, Nishiyama R, Watanabe Y, Vankova R, Tanaka M, Seki M, et al. (2012) Identification and expression analysis of cytokinin metabolic genes in soybean under normal and drought conditions in relation to cytokinin levels. PLoS ONE 7: e42411. doi: 10.1371/journal.pone.0042411 PMID: 22900018

44. Shimizu-Sato S, Mori $\mathrm{H}$ (2001) Control of outgrowth and dormancy in axillary buds. Plant Physiology 127: 1405-1413. PMID: 11743082

45. Takei K, Takahashi T, Sugiyama T, Yamaya T, Sakakibara H (2002) Multiple routes communicating nitrogen availability from roots to shoots: a signal transduction pathway mediated by cytokinin. Journal of Experimental Botany 53: 971-977. PMID: 11912239

46. Mähönen AP, Bishopp A, Higuchi M, Nieminen KM, Kinoshita K, Törmäkangas K, et al. (2006) Cytokinin signaling and its inhibitor AHP6 regulate cell fate during vascular development. Science 311:9498. PMID: 16400151

47. Moreira S, Bishopp A, Carvalho H, Campilho A (2013) AHP6 inhibits cytokinin signaling to regulate the orientation of pericycle cell division during lateral root initiation. PLoS ONE 8: e56370. doi: 10.1371/ journal.pone.0056370 PMID: 23457561

48. Guo Y, Gan S (2011) AtMYB2 Regulates whole plant senescence by inhibiting cytokinin-mediated branching at late stages of development in Arabidopsis. Plant Physiology 156: 1612-1619. doi: 10. 1104/pp.111.177022 PMID: 21543729 
49. Galichet A, Hoyerová K, Kamínek M, Gruissem W (2008) Farnesylation directs AtIPT3 subcellular localization and modulates cytokinin biosynthesis in Arabidopsis. Plant Physiology 146: 1155-1164. doi: 10.1104/pp.107.107425 PMID: 18184738

50. Haberer G, Kieber JJ (2002) Cytokinins. New insights into a classic phytohormone. Plant Physiology 128: 354-362. PMID: 11842139

51. Kakimoto T (2003) Perception and signal transduction of cytokinins. Annual Review of Plant Biology 54: 605-627. PMID: 14503005

52. Deng Y, Dong H, Mu J, Ren B, Zheng B, Ji Z, et al. (2010) Arabidopsis histidine kinase CKI1 acts upstream of HISTIDINE PHOSPHOTRANSFER PROTEINS to regulate female gametophyte development and vegetative growth. Plant Cell 22: 1232-1248. doi: 10.1105/tpc.108.065128 PMID: 20363773

53. Ren B, Liang Y, Deng Y, Chen Q, Zhang J, Yang X, et al. (2009) Genome-wide comparative analysis of type-A Arabidopsis response regulator genes by overexpression studies reveals their diverse roles and regulatory mechanisms in cytokinin signaling. Cell Research 19: 1178-1190. doi: 10.1038/cr.2009.88 PMID: 19621034

54. Hradilová J, Malbeck J, Brzobohatý B (2007) Cytokinin Regulation of gene expression in the AHP gene family in Arabidopsis thaliana. Journal of Plant Growth Regulation 26: 229-244. 